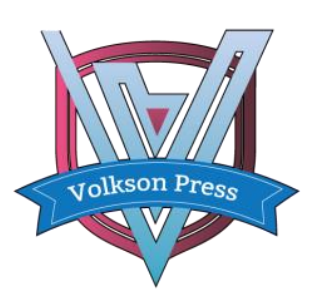

Contents List available at VOLKSON PRESS

New Materials and Intelligent Manufacturing (NMIM)

DOI : http://doi.org/10.26480/icnmim.01.2018.230.232

Journal Homepage: https://topicsonchemeng.org.my/

ISBN 978-1-948012-12-6

\title{
FINITE ELEMENT STRESS ANALYSIS OF THE WELDED INCLINE-BENT PIPE
}

\author{
Yan Zhenhan, Chen Qing* \\ Power Engineering and Engineering Thermophysics, Jilin Institute of Chemical technology, Chengde Street, Jilin City, Jilin, China. \\ *Corresponding Author Email: ChenQing0787@126.com
}

This is an open access article distributed under the Creative Commons Attribution License, which permits unrestricted use, distribution, and reproduction in any medium, provided the original work is properly cited

\section{ARTICLE DETAILS}

\section{Article History:}

Received 26 June 2018 Accepted 2 july 2018 Available online 1 August 2018

\section{ABSTRACT}

In this paper, stress analysis of the welded incline-bent pipe under non-operating condition and operating condition has been analyzed by the means of ANSYS finite element analysis. The results show that the maximum stress of the welded incline-bent pipe is $0.29 \mathrm{Mpa}$ at $0.88 \mathrm{~m}$ of the lower end under the combined action of bending moment. The maximum stress of is $4250 \mathrm{MPa}$ at $0.24 \mathrm{~m}$ around the corner under the joint action of bending moment, internal media pressure and temperature field. Compared to two kinds of conditions found welded incline-bent pipe both at the corner weld of larger stress concentration, and the maximum stress in the operating condition is 15,000 times of the maximum stress under the non-operating condition. Thus the welded incline-bent pipe should try to reduce the additional bending moment and avoid to produce larger stress concentration. In this way, the safety of the welded incline-bent pipe is improved under the condition of installation. The results of this investigation provide some reference for the design of engineering piping.

\section{KEYWORDS}

Welded incline-bent pipe, finite element analysis, non-operating conditions and operating conditions, stress analysis

\section{INTRODUCTION}

Fluids are usually transported and passed through the pipe system in large chemical plants [1]. The most common type of pipe system is the elbow pipe, which plays an important role in the pipe system [2]. In the classification of bend elbow adopts welded miter form is more widely used, the difference between other welded incline-bent pipe is mainly used in oil and gas, water conservancy, electric power, city pipe network. It is generally used in low pressure without the conveying of corrosive medium [3]. The welded incline-bent pipe is welded by a plurality of sectional sections, and its bending angle can be arbitrarily changed. The design of the welded incline-bent pipe in many practical projects is of great significance $[4,5]$.

The most important parameter for designing welded incline-bent pipe is the stress. In the domestic, there are many scholars about the stress analysis of welded incline-bent pipe. For example, some researchers from the chemical machinery college of dalian university of technology [6-8]. They analyzed the stress of the overall stress and the internal pressure bending moment respectively. In abroad countries, the study of welded incline-bent pipe is relatively small, but there are still a lot of literature for reference, and other scholars made A summary and experimental investigation on their stress analysis [9-11]. Based on the research results of various scholars at domestic and abroad, this paper applies the three-dimensional finite element analysis software ANSYS to analyze the stress analysis of the welded incline-bent pipe [12].

\subsection{Geometric model}

The welded incline-bent pipe from the point of view is divided into $90^{\circ}$, $60^{\circ}, 45^{\circ}$. The welded incline-bent pipe geometry is shown in Table 1 [13]. The geometric model is shown in figure 1 [14].
Table 1: Geometric Dimensions of the welded incline-bent pipe

\begin{tabular}{|llccclcll|}
\hline $\begin{array}{l}\mathrm{DN} \\
(\mathrm{mm})\end{array}$ & $\begin{array}{l}\mathrm{D}_{0} \\
(\mathrm{~mm})\end{array}$ & $\begin{array}{c}\delta \\
(\mathrm{mm})\end{array}$ & $\begin{array}{c}\mathrm{R} \\
(\mathrm{mm})\end{array}$ & $\begin{array}{c}\mathrm{a} \\
(\mathrm{mm})\end{array}$ & $\begin{array}{l}\mathrm{b} \\
(\mathrm{mm})\end{array}$ & $\begin{array}{c}\mathrm{L} \\
(\mathrm{mm})\end{array}$ & $\begin{array}{c}\Phi \\
\left({ }^{\circ}\right)\end{array}$ & $\begin{array}{c}\Psi \\
\left({ }^{\circ}\right)\end{array}$ \\
\hline 350 & 377 & 9 & 525 & 378 & 152 & 1000 & 30 & 15 \\
\hline
\end{tabular}

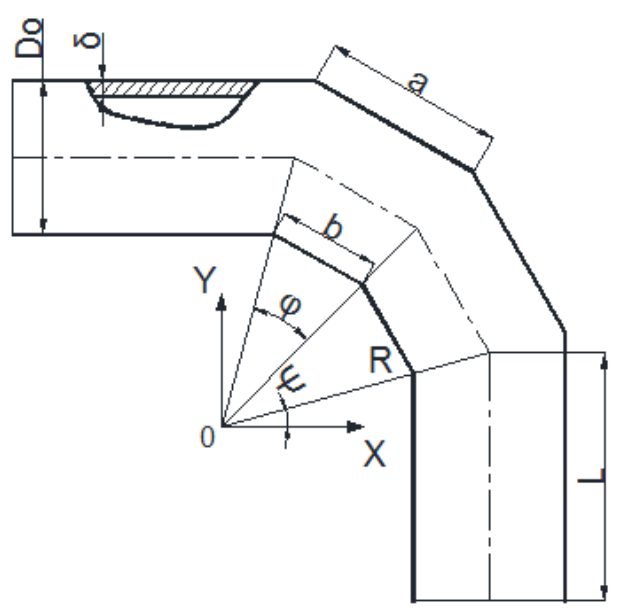

Figure 1: Geometry model of the welded incline-bent pipe

\section{FINITE ELEMENT MODEL}

\subsection{Material properties}

The welded incline-bent pipe is usually made of carbon steel. The material properties are shown in Table 2 [15]. In this analysis, ANSYS finite element analysis software was used to select SOLID186 20Brick block solid unit in the cell [16]. 
Table 2: Properties of Carbon Steel Materials

\begin{tabular}{|c|c|c|c|}
\hline $\begin{array}{l}\text { Young's } \\
\text { Modulus } \\
\text { EX (GPa) }\end{array}$ & $\begin{array}{l}\text { Poisson's } \\
\text { ratio }\end{array}$ & $\begin{array}{l}\text { Density } \\
\left(\mathrm{Kg} / \mathrm{m}^{3}\right)\end{array}$ & $\begin{array}{l}\begin{array}{l}\text { Coefficient of thermal } \\
\text { expansion } \\
\left(10^{-5}\right)\end{array}\end{array}$ \\
\hline 2.1 & 0.3 & 7850 & 1.2 \\
\hline
\end{tabular}

\subsection{Load and boundary conditions}

In this paper, the two different boundary conditions of non- operating conditions and operating conditions are discussed respectively. (1) Under non-operating conditions, one end of the bend is rigidly connected, and one end is loaded by moments. The moments are replaced by $\mathrm{Mx}=$ $1500 \mathrm{~N} \times \mathrm{m}, \mathrm{My}=500 \mathrm{~N} \times \mathrm{m}, \mathrm{Mz}=200 \mathrm{~N} \times \mathrm{m}$ [17]. (2) Under operating conditions, the welded incline-bent pipe add the gravity load and the internal medium load of $1.6 \mathrm{MPa}$ on the basis of the non-operating conditions. The indoor temperature is $20^{\circ} \mathrm{C}$, and the operating temperature is $200^{\circ} \mathrm{C}$. The temperature field is applied to the integral welded incline-bent pipe.

\section{CALCULATION RESULTS AND ANALYSIS}

In the research direction from bottom to bottom, the inner surface of the welded incline-bent pipe is selected as the research path, as shown in figure. 2 .

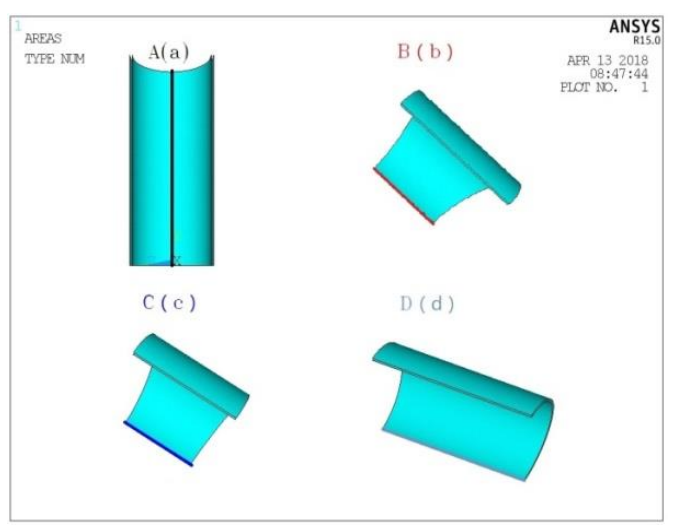

Figure 2: Research pathes identification

\subsection{Analysis of results under non-operating conditions}

\subsubsection{Non-operating stress analysis}

The stress distribution of the welded incline-bent pipe under nonoperating conditions is shown in figure 3. The maximum deformation displacement occurs at the bottom of the welded incline-bent pipe. The displacement value is $\mathrm{X}(\mathrm{DMX})=0.289 \times 10^{-3} \mathrm{~m}$. The maximum equivalent stress occurs on the corner. The maximum equivalent stress value $\sigma_{\max }(\mathrm{SMX})=0.44 \times 10^{-3} \mathrm{MPa}$. The minimum equivalent stress occurs on the outer surface of the welded incline-bent pipe, the minimum equivalent stress $\sigma_{\min }(\mathrm{SMN})=0.29 \mathrm{MPa}$.

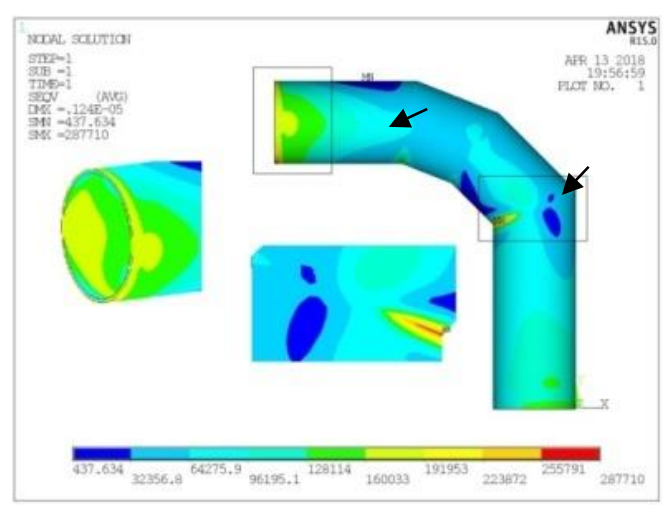

Figure 3: Equivalent stress under operating conditions (Von Mises)

\subsubsection{Non-operating stress-displacement curve}

The displacement stress curve of the non-operating condition is shown in Figure. 4. The $x$-coordinate is expressed as the displacement value, and the $y$-coordinate is expressed as the stress value. As can be seen from the four curves in the figure, it can be seen that the stress tends to be similar to the displacement curve. The stress value decreases with the increase of displacement under non-operating conditions. It can be seen from the a curve that the stress has a sudden change in the displacement value of $0.88 \mathrm{~m}$. It can be seen from the $\mathrm{b}$ curve that when the displacement just occurred, the stress suddenly decreases to a minimum value and then approaches to a certain value, and then it tends to steady. It can be seen from the c curve that the curve path of c curve is not much change and the curve trend is relatively stable. It can be seen from the $d$ curve that the stress changes at $0.58 \mathrm{~m}$ in displacement. At the displacement of $0.88 \mathrm{~m}$, $0.02 \mathrm{~m}$ and $0.58 \mathrm{~m}$, the stress values are all peak, which indicates that stress concentration in these three positions is more prominent, which is consistent with the stress distribution diagram in figure 3.

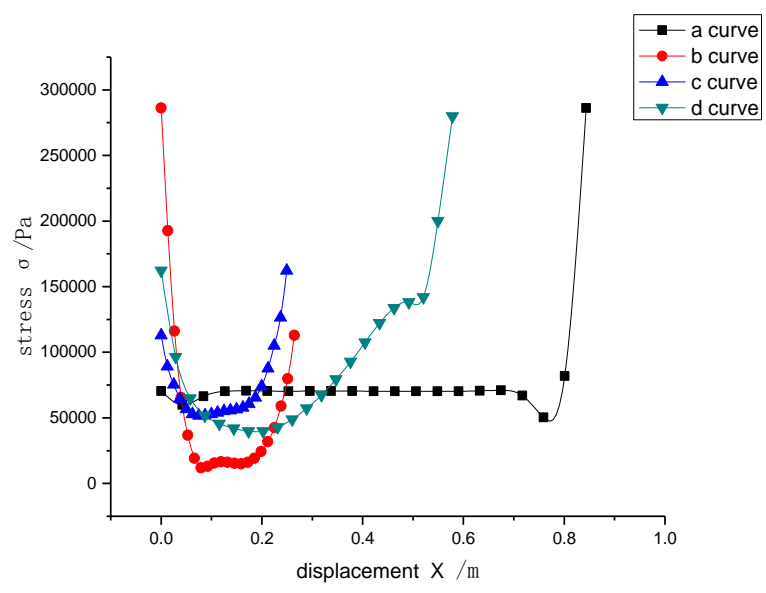

Figure 4: The stress- displacement curves under non-operating conditions

\subsection{Analysis of results under operating conditions}

\subsubsection{Operating stress analysis}

The stress distribution of the welded incline-bent pipe under operating conditions is shown in figure.5. The maximum deformation displacement occurs at the lower end of the welded incline-bent pipe, and the displacement value is $\mathrm{X}(\mathrm{DMX})=0.12 \mathrm{~m}$. The maximum equivalent stress occurs at the corner of the bend, the maximum equivalent stress value $\sigma_{\max }(\operatorname{SMX})=4250 \mathrm{MPa}$. The minimum equivalent stress occurs at the bottom of the welded incline-bent pipe, and the minimum equivalent stress $\sigma_{\min }(\mathrm{SMN})=8.2 \mathrm{MPa}$.

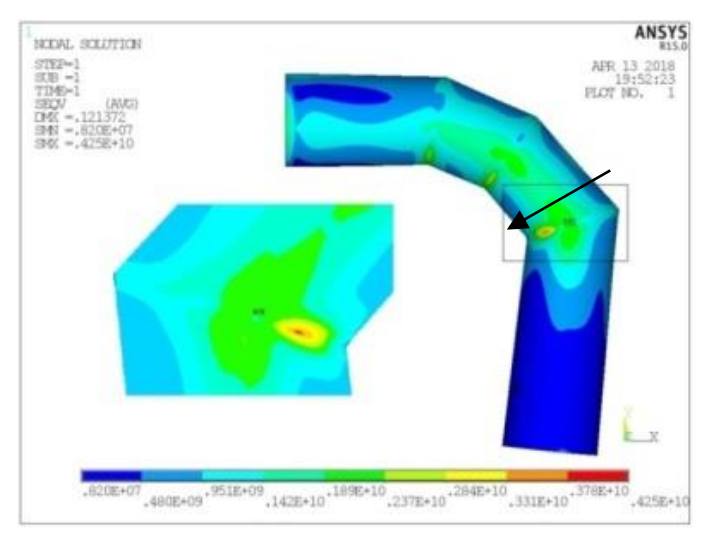

Figure 5: Equivalent stress under operating conditions (Von Mises)

\subsubsection{Operating condition stress-displacement curve}

The four curve stress changes with the displacement is different from the stress displacement curve generated under non-operating conditions, as 
shown in Figure 6. It can be seen from the A curve that the increase of displacement first decreases and then increases. The stress value at the displacement of $0.22 \mathrm{~m}$ is $0 \mathrm{MPa}$. From B and C both curve can be seen that the final stress value is large. It can be seen from the $\mathrm{D}$ curve that the stress value of the inclined elbow always decreases as the displacement increases. The minimum value occurs at the $0.22 \mathrm{~m}$ point of the A curve and the maximum stress value occurs at the $0.24 \mathrm{~m}$ point of the $\mathrm{C}$ curve. This indicates that the stress points are the most stress points in these two positions and are consistent with the stress distribution diagram of the welded incline-bent pipe under the operating conditions in Figure. 5.

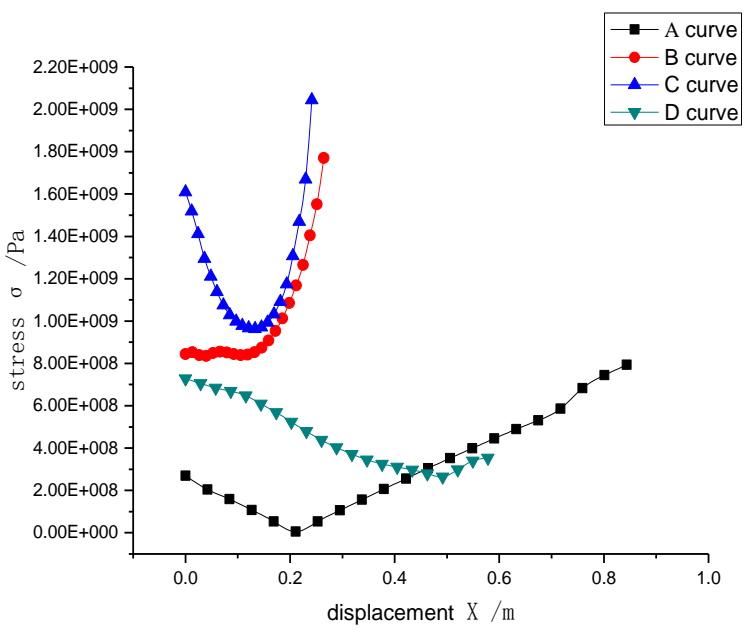

Figure 6: The displacement-stress curve under operating conditions

\subsection{Comparison of results under two conditions}

(1) Due to the non-continuation of the material at the welding corners of the welded incline-bent pipe, the curvature is not uniform and the stress concentration is significant.

(2) The deflection displacement of welded incline-bent pipe under operating conditions is 100,000 times larger than that under nonoperating conditions.

(3) The stress value of the welded incline-bent pipe under operating conditions also increases significantly. The internal pressure and temperature load have a great influence on the welded incline-bent pipe.

\section{CONCLUSION}

(1) From the displacement-stress curve Figure.5, the trend of the four curves is similar under non-operating conditions. The maximum stress occurs at the weld corner where a curve is $0.88 \mathrm{~m}, \mathrm{~b}$ curve is $0.02 \mathrm{~m}$, and $\mathrm{d}$ curve is $0.58 \mathrm{~m}$.

(2) From the displacement-stress curve Figure.7, it is seen that the trend of the four curves is irregular under operating conditions. The maximum stress occurs at the welding corner where the $C$ curve is $0.24 \mathrm{~m}$. The moment load under the installation conditions should be appropriately reduced, so as to ensure design engineering piping safety.

\section{REFERENCES}

[1] Yue, J.C. 2006. Pressure pipe technology. Beijing: Sinopec Press, 13-16.

[2] Shen, S.Q., Huang, Z.R., Gu, J.C. 2004. Safety Technology of Pressure Pipelines. Nanjing: Southeast University Press.

[3] Tang, Y.J. 2009. Stress Analysis of Pressure Pipelines. 2nd Edition. Beijing: Sinopec Press, 51-66.

[4] Hu, J.H. 2009. Installation Process of Stainless Steel Large-diameter Steel Elbow Assembly. Engineering Science, 133-136.

[5] Shaikh, M.M., AlSuhaimi, A.O., Hanafiah, M.M., Ashraf, M.A., Fantoukh, A., AlHarbi, E. 2017. Leachable Volatile Organic Compounds from Polyethylene Plumbing Plastic Pipes: a case study of Medina Al Munawarah, Saudi Arabia. Acta Chemica Malaysia, 1 (1), 01-03.

[6] Xiao, C.B., Li, H.R. 2004. Finite Element Analysis of the Stress of Welded Pipe Bending Tube. Petrochemical Equipment, 6(3), 28-29.

[7] Li, H.M., Li, H.R. 2008. Finite Element Solutions for the Penetration Crack of Welded Pipe under Internal Pressure and Bending Moment. Chemical Equipment Technology, 6 (5), 50-52.

[8] Du, G.Q., Wang, Z.Y. Analysis of the Fracture Parameters of the Cracked Shrimp in the Waist. China Petroleum and Chemical Standards and Quality.

[9] Shahani, A.R., Shodja, M.M., Shahhosseini, A. 2010. Experimental Investigation and Finite Element Analysis of Fatigue Crack Growth in Pipes Containing a Circumferential Semi-elliptical Crack Subjected to Bending. Experimental Mechanics, 6 (10), 563-573.

[10] Pimshtein, P.G., Kabanova, O.E. 2012. Evaluation of Residual Postbending Stresses in Pipe Fittings. Chemical and Petroleum Engineering, 4 (9), 345-348.

[11] Fontana, F., Viotti, M.R. 2016. Bending Stress Determination in a Pipe Test Bench Using DSPI Combined with Instrumented Indentation. Experimental Mechanics, 5 (6), 713-722.

[12] Zhao, F.X., Zhou, P.F., Qian, Y.H. 2016. Analysis of Pipeline Deformation Stress Based on ANSYS. Chemical Equipment Technology, 6 (4), 47-52.

[13] Xu, S.H. 2001. $90^{\circ}$ Bend Stress Distribution. Journal of Chemical Equipment and Pipeline, 5 (8), 38-39.

[14] Chen, Q., Zhao, M.J. 2004. Stress Analysis of Olique Bnd under Eternal Lad. Pressure vessel. 4 (2).

[15] GB 150-2011. Steel Pressure Vessels.

[16] Sui, Z.F., Hao, D. 2008. The application of ANSYS in the Stress Analysis of Fixed Posterior Wall Pipes. GuiZhou Chemical Enginee, 8 (12), 33-37.

[17] De'nan, F., Nazri, F.M., Hashim, N.S. 2017. Finite Element Analysis on Lateral Torsional Buckling Behaviour Oi I-Beam with Web Opening. Engineering Heritage Journal, 1 (2), 19-22. 